Чемезова Е. Р.

Аннотация. Цель исследования - выявить парадигму фиксаций трансформированных фольклорных образов Зеленого человека в текстах литературы англоязычных стран. В статье проясняются мифологические и фольклорные прообразы большинства вариантов репрезентации образа Зеленого человека в поэме «Сэр Гавейн и Зеленый Рыцарь», комедии У. Шекспира «Виндзорские насмешницы», романе У. Х. Эйнсворта «Виндзорский замок» и новелле В. Ирвинга «Сонная лощина», а также выявляются модели их функционирования в каждом тексте. Научная новизна исследования заключается том, что вопрос репрезентации и трансформации образа Зеленого человека (Кернунна) оставался на маргинесе литературоведческих исследований. В результате доказано, что встречающиеся в англоязычной литературе образы - от Зеленого Рыцаря до Всадника без головы - восходят к традиционным цикличным формам бога Луга.

\title{
Image Transformation in the English-Speaking Countries Literature
}

\section{Chemezova E. R.}

\begin{abstract}
The purpose of the study is to identify the paradigm of the Green Man's transformed folklore images recorded in the texts belonging to the literature of the English-speaking countries. The article clarifies mythological and folklore prototypes of most representation variants of the Green Man's image in the poem "Sir Gawain and the Green Knight”, W. Shakespeare's comedy “The Merry Wives of Windsor”, W. H. Ainsworth's novel "Windsor Castle" and W. Irving's short story "The Legend of Sleepy Hollow" and also identifies models of their functioning in each text. Scientific novelty of the study lies in the fact that the issue of the Green Man's (Cernunnos's) image representation and transformation has remained on the margins of literary criticism. As a result, it is proved that the images found in the English-language literature, ranging from the Green Knight to the Headless Horseman, go back to traditional cyclical forms of god Lugh.
\end{abstract}

\section{Введение}

Актуальность темы исследования обусловлена значительным влиянием Зеленого человека как архетипического образа мужского божества в англоязычной литературе. Зарубежная литература изобилует фольклорными образами, которые встречаются не только в архетипически целостной, но и в трансформированной форме. Необычным является «передвижение» образов из индоевропейской мифологии и фольклора вместе с группами переселенцев на территории Великобритании и США, что можно отследить в ходе нашего исследования. Особый интерес представляет образ так называемого Зеленого человека, который пришел из фольклора и претерпел поэтапную трансформацию от Кернунна (Рогатого Бога) до Всадника без головы.

Для достижения цели исследования необходимо решить следующие задачи: во-первых, выявить особенности образа Зеленого человека и похожих мужских божеств; во-вторых, описать этот образ в поэме «Сэр Гавейн и Зеленый Рыцарь»; в-третьих, проследить его трансформации в других исследуемых текстах.

Для анализа образа Зеленого человека и его трансформаций в англоязычной литературе в статье применяются следующие методы исследования: системный подход и метод литературной герменевтики. С помощью системного подхода обеспечивается аналитическое описание характеристик репрезентаций образов Зеленого человека и его трансформаций в мифологии и литературных текстах. Метод литературной герменевтики применяется для интерпретации образов и их парадигм. 
Теоретическая база исследования представлена работами ученых, касавшихся образа Всадника без головы при обращении к тексту поэмы «Сэр Гавейн и Зеленый Рыцарь» (М. А. Волконская [1], Ю. П. Вышенская [2], А. А. Шарапкова [6] и др.). В существующих публикациях внимание исследователей привлекали стилистические и языковые аспекты поэмы, но образ Всадника и его эволюция оставались на маргинесе литературоведческих изысканий.

Практическая значимость работы заключается в том, что ее результаты могут быть использованы в преподавании курсов по истории зарубежной литературы, истории литературы англоязычных стран, для разработки спецкурсов, посвященных изучению мифологии и фольклора англоязычных стран.

\section{Мужские божества фольклора Британских островов}

В рамках истории литературы англоязычных стран образ Зеленого человека подвергается видоизменениям, что связано с различиями в мифологических и фольклорных сюжетах. Его отличительная особенность заключается не столько в колористическом компоненте, сколько в наличии характеристик, связанных с головой. Первообраз восходит к мифологии Британских островов и образу Кернунна, так называемого Рогатого Бога. Считается, что наиболее архаичный пласт образа Кернунна - это представление о Хозяине Леса, божестве плодородия и охотников. Возможно, он был духом принесенного в жертву бога-оленя, который должен был дать богатство дичи, что соответствует «айнскому типу жертвоприношения» [5] (его основной элемент отсечение головы животного). Британский фольклор сохранил несколько другую парадигму Рогатого Бога, связанную с охотой: он выступает в роли охотника, а не жертвы. Однако мифопоэтическому мышлению свойственно сближать оппозиции, что помещает определения охотника и жертвы не так далеко друг от друга.

В тексте легенды «Кухулин и Кернунн» есть момент встречи героя с Кернунном и смены обличья: «...его взору предстал прекрасный белый олень с ветвистыми рогами необыкновенной красоты. ...золотой торквес украшал шею оленя. Неожиданно животное начало светиться... и он увидел статного мужчину в искусно расшитых одеждах. Сетанта догадался, что перед ним сам Кернунн-Луг» [3, с. 37]. Герой с Кернунном отправляются в потусторонний мир через дольмен. В этом видении объясняются происхождение эпического героя и его связь с Кернунном: первый оказывается сыном второго, и именно в этой легенде юноша получает оружие копье Немеда, имеющее сакральное значение для кельтов и ирландцев.

Как отмечает М. Симос, «Рогатый Бог олицетворяет силу чувств. Его звериные рога олицетворяют истину нескрываемых эмоций, которые не стремятся угодить хозяевам. Он не приручен. Но необузданные чувства сильно отличаются от разыгранного насилия. Рогатый Бог - это жизненная сила, жизненный цикл. Он остается в кругу Богини; его сила всегда направлена на служение жизни» [16].

Признаки, такие как рога, создают единую общность образа Кернунна, которая фигурирует во всех его фиксациях. Обращаясь к «Словарю символов» Дж. Тресиддера, стоит отметить, что рога - это «сила, могущество, мужественность, плодовитость, верховная власть - символ богов. Для древних рога... были символом мужского боевого духа и фаллической силы. Отсюда популярность и высокий статус рогатых божеств, особенно в обществах, основанных на скотоводстве и охоте. Кельтские рогатые боги символизировали богатый урожай. Ранние изображения рогатых фигур в наскальной живописи - запись шаманских заклинаний для успешной охоты. <..> В Библии рога - символ силы или, в Новом Завете, - спасения. Христианство скоро обратилось против поклонения рогам, которые стали знаком сатаны и его рогатых последователей» [4]. Взаимосвязь между изменением значения Рогатого Бога в ранних текстах и в текстах с христианским влиянием представляет особый интерес.

Рогатый Бог связан с Дикой охотой, в этом варианте он выступает как «жнец», дух-психопомп со стаей черных псов (“black hounds” [15]), луком и стрелами в руках. Британский легендарный персонаж Хернохотник также считается трансформацией Кернунна, которая демонстрирует, как божество утрачивает признак рогатости. Херн уже связан с легендами о Робине Гуде, и он, точно так же как Робин, добывает средства для нуждающихся; Херн дает пищу своему племени, а в некоторых мифах он фигурирует как отец Робина Гуда, хотя, возможно, это было сделано для повышения статуса легенд и баллад.

Рогатый Бог отождествляется с цикличностью года, он также может выступать в двух противостоящих друг другу ипостасях - Король Дуб (летнее божество с густой листвой по всему телу и рогами) и Король Падуб (зимнее божество, часто всадник-мертвец).

Так, мы можем выделить несколько мифологических характеристик, которые присущи образу Кернунна: 1) цикличность (изменение внешнего вида в зависимости от времени года); 2) соотнесенность с зеленым цветом листвы как в летний, так и в зимний период; 3) наличие оленьих рогов на голове; 4) отождествление с плодородием (мужской силой) и богатством леса; 5) функционирование в качестве Охотника, сопровождаемого черными псами в Дикой охоте; 6) богатое и искусно вышитое золотом облачение.

\section{Репрезентация образа Зеленого человека в поэме «Сэр Гавейн и Зеленый Рыцарь»}

Мы можем проследить, как исторически привычный и архетипический образ мужского божества преобразуется в ходе времени. В поэме «Сэр Гавейн и Зеленый Рыцарь» завязка происходит в Камелоте в Рождественские святки, сопровождающиеся пиром. В зал является Зеленый Рыцарь на коне: “On pe most on pe 
molde on mesure hyghe; / Fro pe swyre to pe swange so sware and so pik, / And his lyndes and his lymes so longe and so grete, / Half etayn in erde I hope pat he were, / Bot mon most I algate mynn hym to bene... / He ferde as freke were fade, / And oueral enker-grene. <...> Al studied pat per stod, and stalked hym nerre / Wyth al pe wonder of pe worlde what he worch schulde. / For fele sellyez had pay sen, bot such neuer are” [18]. Следует отметить характеристику классического образа Зеленого Рыцаря, которая дается в произведении, и ее связь с архетипическим образом Кернунна. Ключевым моментом является упоминание зеленого одеяния с богатым вышитым украшением. Сам зеленый цвет «является также цветом Ирландии, “Изумрудного острова”, - эпитет, связанный с кельтской традицией, в соответствии с которой добродетельные души отправлялись в путешествие на зеленый Остров блаженных (Tirnan Og). Изумрудно-зеленый - христианская эмблема веры, цвет Святого Грааля. Зеленый встречается как цвет Троицы, Откровения и в раннем христианском искусстве - цвет креста и иногда одежды Девы Марии. <...> Хотя зеленый - цвет природы и чувственного мира, он часто связан с потусторонним миром - это мистический цвет эльфов... Сатану иногда изображают зеленым» [4]. Образ Зеленого Рыцаря во многом соответствует символическому значению цвета, ведь в произведении Зеленый Рыцарь, прибыв к Круглому столу Артура, предлагает сыграть в игру на отсечение его головы его же топором. Только Гавейн соглашается на игру и отсекает голову Рыцаря, которая сообщает ему, что через год и один день в Зеленом лесу у Зеленой часовни он заберет долг.

Автор поэмы «Сэр Гавейн и Зеленый Рыцарь» не просто так проводит параллель между Зеленым Рыцарем и йотуном (etayn). Йотун - гигант в германо-скандинавской мифологии, природный дух со сверхчеловеческой силой, противостоящий расам асов и ванов, хотя они часто смешивались или даже состояли в браке с йотунами. В некоторых легендах и мифах йотуны одного роста с людьми.

Сходство мифологического мотива вторжения, описанного в начале поэмы «Сэр Гавейн и Зеленый Рыцарь», обращает нас к мифу о Торе и йотуне Грунгнире с каменной головой. В поединке, который описан в “Skáldskaparmál” («Языке поэзии»), молот Тора попал в середину головы Грунгнира и разбил его череп на мелкие фрагменты, и йотун упал вперед через Тора, обезглавленный. Сначала Грунгнир, посетив Асгард, угрожает асам уничтожением их обители, а после Тор приходит в Йотунхейм, там вступая в финальную битву с йотуном. Их битва носит хтонический характер - это битва древнего зла, хаотического начала и нового порядка, установленного асами. Так и в поэме мы наблюдаем битву древнего хтонического божества, Кернунна (Зеленого человека / Рогатого Бога), с христианским новым законом. Прослеживается и хронотопическая взаимосвязь мотивов: герои нового времени вступают в финальную битву с антагонистом на его территории, что происходит через определенный промежуток времени после вторжения «древнего зла»на их территорию. Ключевое отличие мотива заключается в том, что в поэме показана связь между языческим и христианским. Гавейну в его путь к Зеленому Рыцарю преподносят щит: “Then pay schewed hym pe schelde, pat was of schyr goulez / Wyth pe pentangel depaynt of pure golde hwez. / Pat bisemed pe segge semlyly fayre. / And quy pe pentangel apendez to pat prynce noble" [18]. Несмотря на довольно христианизированную дальнейшую интерпретацию и факт нанесения пентаграммы на пурпурный фон, который прямо противопоставляется в колористике оттенкам зеленого, мы видим классический пример использования языческого символа.

Особое внимание стоит уделить тому факту, что Зеленый Рыцарь приходит с остролистом (падубом) в рукаx: "Bot in his on honde he hade a holyn bobbe" [Ibidem]. Это свидетельство его связи с Королем Падубом, зимней ипостасью Кернунна в классической мифологии. В комментариях к поэме Дж. Р. Толкин отмечает также, что «ветка вечнозеленого остролиста (или падуба) в руке великана служит символом мира. Как правило, посланцы в Средние века приезжали с оливковой ветвью, но падуб еще с дохристианских времен ассоциировался с празднованием Нового года. В данном случае все детали вплетаются в нарочито двусмысленную картину: в другой руке Зеленый Рыцарь держит устрашающих размеров топор, который, надо думать, выглядел более выразительным символом» [Ibidem]. Оппозиции «мир / война» и «христианство / язычество» становятся основой сложного мировосприятия, представленного в поэме, автор которой был современником Дж. Чосера и делал акценты на подобных деталях.

Когда Гавейн является в Зеленый лес и встречается с Бертилаком, у которого гостит, мы можем проследить соединение образа Зеленого человека, Кернунна, с Херном-охотником. Мотив охоты демонстрирует различные стадии игры, в которую божество леса, Кернунн, играет с Гавейном. Предлагаемая игра вращается вокруг обмена выигрышем: Бертилак будет проводить каждый день на охоте и отдавать плоды охоты своему гостю. Гавейн может проводить время в замке как угодно в компании жены Бертилака и других, и в конце дня он должен вернуть Бертилаку все, что приобрел за это время.

В первый вечер Бертилак возвращается с охоты с большим количеством оленей, все они переданы его гостю, после чего Гавейн целует его. В конце второго дня охотник возвращается с могучим кабаном, в обмен на которого сэр Гавейн дарит ему два поцелуя. Когда его спрашивают, как он получил эти прекрасные подарки, Гавейн отвечает, что не скажет, потому что это не было условием сделки. Причина была в том, что поцелуи были подарены женой Бертилака, когда она пыталась соблазнить рыцаря в его спальне. К третьему вечеру она открыто ухаживает за ним и снимает зеленый шелковый пояс со своей талии, надевая его на Гавейна. Она говорит ему, что это талисман и что ему нельзя навредить, если он его наденет. Так он может избежать смерти от рук своего противника.

Сама охота является естественной формой функционирования Рогатого Бога. Охотничье божество Херн является проявлением Кернунноса, кельтского рогатого бога. Поскольку он встречается только в Беркшире, а не в остальной части Виндзорского леса, Херн считается «локализованным» богом и действительно может 
быть беркширской интерпретацией Кернунна. Район Виндзорского леса находится под сильным саксонским влиянием. Одним из богов, почитаемых первыми поселенцами региона, был Один, известный тем, что путешествовал по небу во время собственной Дикой охоты. Рога Херна сближают его с оленем, удостоенным большого почитания. В конце концов, убийство одного оленя могло означать разницу между выживанием и голодом, так что это было значимым для того времени. Херн считался божественным охотником, и на Дикой охоте его видели с большим рогом и деревянным луком верхом на черной лошади в сопровождении стаи лающих гончих.

Подтверждение связи Бертилака (Зеленого Рыцаря) с образом Кернунна (Рогатого Бога) появляется именно в контексте охоты. Ранее было отмечено, что Кернунн - божество леса и охоты. Оно ассоциируется с оленями, рогатыми змеями, собаками, быками и крысами [8, р. 147]. Некоторые видят качества Кернунна в жизни святого Киарана из Сайгира, одного из двенадцати апостолов Ирландии. Когда он строил свою келью, его первым учеником и монахом был кабан, которого Бог сделал кротким. Затем последовали лиса, барсук, волк и олень [13]. Это показывает нам, что образ Кернунна христианизируется, как и в случае с Зеленым Рыцарем.

В последний вечер Бертилак возвращается, извиняясь, ему стыдно признать, что за день он убил лишь одну лисицу. Сэр Гавейн в свою очередь передает трофеи своего дня в виде трех поцелуев, но о поясе не говорит ничего. Следует отметить, что Бертилак, который по сути своей является Зеленым Рыцарем, ипостасью Кернунна, преподносит Гавейну лисицу не просто так. Он изначально, как божество леса, знает о его лжи, и поэтому именно лиса становится его даром Гавейну. Лисица - это символ «хитрости, дополняемый в европейской традиции злобой, лицемерием, пороком. Лиса стала в христианстве аналогией уловок дьявола» [4]. Подверженность честного рыцаря Круглого стола греху является свидетельством его человеческой натуры, которая поддалась на искушения семейства Бертилаков. Так, Леди Бертилак и сам Бертилак - не кто иные, как Рогатый Бог (Кернунн) и Богиня, которые в процессе христианизации стали отождествляться с образами Сатаны и Лилит.

Рано утром следующего дня Гавейна приводят на вершину холма, с которой он может увидеть местонахождение Зеленой часовни. Проводник предлагает ему уехать в другом направлении и утверждает, что он сохранит секрет. Гавейн отказывается, благодарит человека за его услуги и продолжает спускаться в долину к месту назначения. Когда он прибывает в место, указанное проводником, он не видит ничего, кроме холма в роще вечной зелени. Но из-за насыпи доносится звук стали, жужжащей о точильный камень. Гавейн взывает к своему противнику. Зеленый Рыцарь приближается с головой на плечах, без следов шрама на шее, с юпитерианской манерой восклицая, насколько пунктуальным и храбрым должен быть рыцарь, чтобы выполнить свое назначение. Сэр Гавейн не любит тратить время на банальные разговоры и предлагает ему заняться своим делом. Поэтому он снимает плащ и становится на колени на заснеженной земле, сцепив руки за спиной и прижавшись лбом к земле. Зеленый Рыцарь встает и заносит топор [14]. Только на третий раз Зеленый Рыцарь наносит племяннику Артура рану на шее.

Важным моментом в противостоянии Гавейна и Зеленого Рыцаря является образ действий Зеленого Рыцаря: он поздравляет Гавейна с его замечательным поведением под чарами его жены-ведьмы Морган Ле Фэй и показывает, что именно она придумала выходку и маскировку для проверки достоинств братства Круглого стола. Бертилак впечатлен стойкостью и поступками Гавейна перед лицом невероятных препятствий и предлагает ему вернуться в замок и отпраздновать завершение приключения. Но Гавейн хочет только как можно скорее покинуть это место и никогда больше не возвращаться, чувствуя себя обманутым и пристыженным. Здесь видна вариация мифа о Кухулине и Кернунне - охотившийся Кухулин получает от Кернунна только лишь одобрение и дары, но не осуждение за прошлые поступки.

Многое в образе Зеленого Рыцаря в поэме «Сэр Гавейн и Зеленый Рыцарь» обращает нас к тому, что Бертилак является Рогатым Богом, но только лишь тот факт, что Зеленый Рыцарь позволяет отрубить себе голову и вполне естественно функционирует часть поэмы без нее, держа ее в руках, акцентирует наше внимание на том, что данный образ заимствован из фольклора Ирландии. Именно в ирландском фольклоре впервые встречается так называемый Всадник без головы, Дюллахан. Б. Хаггерти пишет, что «после захода солнца, в определенные праздники и праздничные дни, можно увидеть одно из самых ужасных существ в мире духов, Дюллахана, едущим на великолепном черном жеребце через сельскую местность. Где бы он ни остановился, смертный умирает. Одетый в развевающиеся черные одежды, Дюллахан не имеет головы на плечах. Он носит ее с собой в руке, и, поскольку он наделен сверхъестественным зрением, он будет высоко держать голову. Это позволяет ему видеть на большие расстояния даже в самую темную ночь. Если он заметит, что вы наблюдаете за ним, то выльет на вас ведро крови или заберет один глаз. Однако самое страшное, если он остановится, где бы вы ни находились, и назовет ваше имя. Это вытянет вашу душу, и вы больше не будете среди живых» [9].

В отличие от банши, которая, как известно, предупреждает о неминуемой смерти в определенных семьях, Дюллахан не приходит предупреждать. Он явный предвестник чьей-то кончины, и против него нет никакой защиты, кроме предмета из золота. По какой-то причине у Дюллахана есть иррациональный страх перед золотом, и даже крошечной суммы может хватить, чтобы его отпугнуть. Подобное описание, несомненно, подчеркивает яркие отличия Дюллахана и Зеленого Рыцаря: Зеленый Рыцарь облечен в зеленый, вышитый золотом костюм, и его конь также зеленый, а Дюллахан боится золота, и его одеяние черное. Зеленый Рыцарь приходит испытать Камелот своей формальной смертью (отсечение головы), а Дюллахан приходит лишить жизни других.

Б. Хаггерти утверждает, что происхождение Дюллахана связано с кельтской мифологией, как и история рыцарей Круглого стола и Зеленого Рыцаря, и что Дюллахан является воплощением кельтского бога плодородия Крома Дабха (или Крома Круаха), которому поклонялся древний король Ирландии Тигермас. Стоит отметить, что Кром Круах часто рассматривается как один из образов бога Луга, которого отождествляли с Кернунном и с которым встречался Кухулин. Каждый год кельты и ирландский король Тигермас приносили людей в жертву 
Крому Дабху, и обычным методом было обезглавливание. Поклонение Крому Дабху закончилось в VI в., когда в Ирландию пришло христианство. Но его не так легко забыть, поскольку говорят, что он тогда «принял физическую форму - безголового Дюллахана, что означает “темный человек”, оседлавшего своего могущественное скакуна и использующего человеческий позвоночник в качестве хлыста» [Ibidem].

Связь между образами Зеленого Рыцаря и Дюллахана, а также между их трансформациями и мифологическими прообразами можно изобразить схематически (см. Рис. 1).

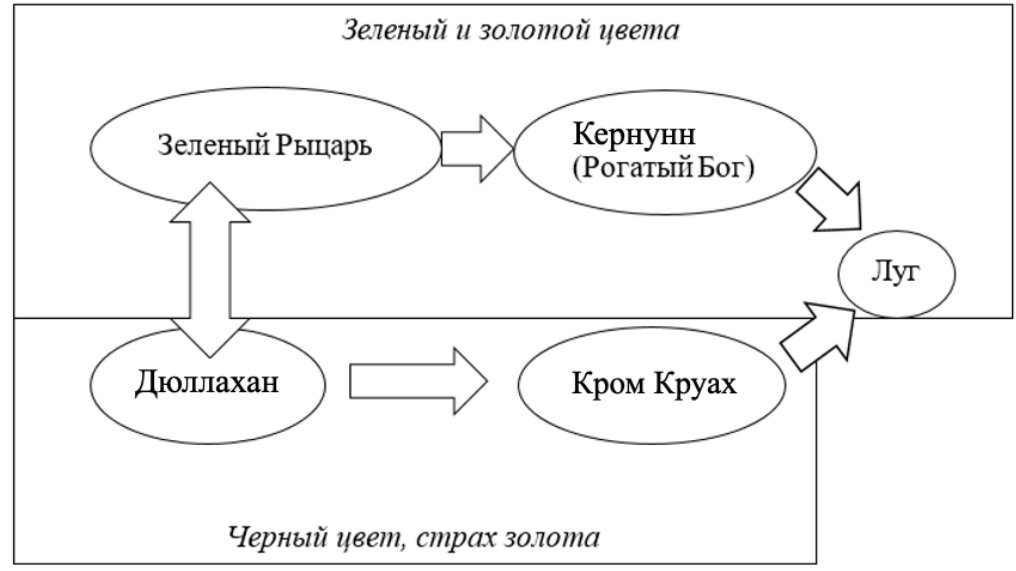

Рисунок 1. Трансформация образа Зеленого Рыцаря в поэме «Сэр Гавейн и Зеленый Рыцары»

Исключительной особенностью выделенного первообраза, к которому восходят Зеленый Рыцарь и Дюллахан, является соответствие Луга «светлой» стороне Колеса года, в ходе которого сменяются обычно характеристики мужских божеств. Так, Луг отождествляется с формой панкельтского / галльского бога Лугуса / Лугоса. Луг был известен как бог Солнца и как жестокий воин. Он также известен как бог бурь, особенно гроз. Он был связан с вороном и рысью, и у него была гончая [7]. Согласно ирландской традиции, сыном Луга или перерождением был великий герой Ульстера Кухулин [12], о чем говорилось ранее.

Несмотря на столь активные и глубинные обращения к мифологическому образу «светлого» божества Луга, дальнейшие использования образа Зеленого человека в англоязычной литературе представлены в качественно новой вариации, которая обращает нас именно к «темной» стороне Колеса года из традиций германских и кельтских народов.

\section{Трансформации образа Кернунна в английской литературе}

Самой популярной трансформацией образа Кернунна стало упоминание его в качестве Херна-охотника в пьесе У. Шекспира «Виндзорские насмешницы» (1587). Шекспировский Херн - это человеческий призрак.

Неизвестный писатель XVIII века утверждал, что Херн был хранителем леса, который боялся потерять работу из-за совершенного им «серьезного проступка», и поэтому повесился на дереве. Однако именно викторианский готический писатель У. Х. Эйнсворт ответственен за дальнейшую популяризацию некоторых аспектов легенды о Херне-охотнике. Роман У. Х. Эйнсворта «Виндзорский замок» (1843) - это мелодрама, действие которой происходит во время правления Генриха VIII в замке и вокруг него, а самым ярким персонажем в ней является Хернохотник из «Виндзорских насмешниц». У. Шекспир сделал Херна призраком егеря в королевском лесу Виндзора, который появлялся посреди зимних ночей возле дуба и имел оленьи рога, как и Кернунн. Я. Гримм предположил в начале XIX века, что персонаж Херна-охотника, возможно, был английской версией североевропейского языческого бога, который руководил Дикой охотой. Шекспировский Херн ни на чем не ездил верхом, у него не было свиты собак, и он даже не охотился. Похоже, что только его рога, появление ночью и неопределенный фольклорный аспект стали для Я. Гримма основанием для того, чтобы связать Херна с Дикой охотой.

Херн У.Х. Эйнсворта представляет собой сочетание оригинальной отсылки к У. Шекспиру и фольклорного наследия Я. Гримма. У. Х. Эйнсворт в 31 главе «Виндзорского замка» объясняет, что Херн был человеком, но заключил ужасную сделку с дьяволом, который спас ему жизнь, когда его забодал олень, с условием, что он будет вечно носить рога. В конце концов дьявол лишил его навыков охотника, доведя до отчаяния, самоубийства и проклятия. Херн У. Х. Эйнсворта - призрак человека, но теперь он также демонический, сопровождаемый бесами и заключающий договоры с людьми, чтобы исполнять желания взамен их душ. Мало того, теперь он едет на огнедышащем черном коне, а рядом с ним бегут черные собаки, а также множество мертвых людей, особенно казненных преступников, и живых людей, которые принесли ему клятву верности [10].

«Связав Херна с дьяволом, У. Х. Эйнсворт проложил путь новым интерпретациям, которые рассматривают его как нечто большее, чем просто человека - лидера Дикой охоты, лесного духа, аватара Кернунна. Все это очень далеко от У.Шекспира»[17, р.137]. Ключевым моментом является тот факт, что до У. Шекспира нет 
фиксированных упоминаний Херна-охотника в литературных памятниках, а это говорит о том, что это прежде всего новый образ, созданный У. Шекспиром на основе образа Кернунна и локализованный в королевском лесу.

\section{Специфика образа Кернунна в новелле В. Ирвинга «Легенда о Сонной Лощине»}

Несмотря на активную новую локализацию образа Кернунна и ее облеченность авторами в «темную» ипостась, в американской литературе также появляются новые варианты. Так, например, В. Ирвинг в новелле «Легенда о Сонной Лощине» представляет нашему вниманию образ участника Дикой охоты, или Дюллахана.

Дж. Трейнор придерживается мнения, что «самой известной и устойчивой версией фигуры Дюллахана должен быть всадник без головы, изображенный в новелле В. Ирвинга “Легенда о Сонной Лощине”, действие которой происходит в сельской местности Нью-Йорка. <...> Интересно видеть, как кельтские корни этой истории просачиваются через историю Америки того времени. “Сонная лощина” - это не только сатира на материалистические общины голландских поселенцев, но и история о фольклорных призраках» [19].

Обращаясь к описанию Всадника без головы из новеллы В. Ирвинга, следует отметить, что сам он уже не Дьявол во плоти и не фольклорный дух, а умерший на поле боя солдат. Описание встреч поселенцев с Всадником без головы обращает нас уже к фольклорным элементам, дополняющимся локацией и внешним обликом в подробных деталях: “...the road that led to it, and the bridge itself, were thickly shaded by overhanging trees, which cast a gloom about it, even in the daytime; but occasioned a fearful darkness at night. Such was one of the favorite haunts of the Headless Horseman, and the place where he was most frequently encountered. The tale was told of old Brouwer, a most heretical disbeliever in ghosts, how he met the Horseman returning from his foray into Sleepy Hollow, and was obliged to get up behind him; how they galloped over bush and brake, over hill and swamp, until they reached the bridge; when the Horseman suddenly turned into a skeleton" [11]. Здесь В. Ирвинг обращает наше внимание на то, что Всадник без головы находится в месте, где густо растут деревья, которые практически создают мрак, и этот факт отсылает нас к тексту поэмы «Сэр Гавейн и Зеленый Рыцарь», где указывалось, что в Зеленом лесу, принадлежавшем Бертилаку, сумрачно из-за густых крон деревьев. Кроме того, мы видим новую внешнюю характеристику: Всадник без головы представляется скелетом, что ранее не фиксировалось в фольклорных источниках.

Сама встреча Икабода, главного героя новеллы В. Ирвинга, с Всадником без головы уже более детализирована: "Just then the shadowy object of alarm put itself in motion, and with a scramble and a bound stood at once in the middle of the road. Though the night was dark and dismal, yet the form of the unknown might now in some degree be ascertained. He appeared to be a horseman of large dimensions, and mounted on a black horse of powerful frame. He made no offer of molestation or sociability, but kept aloof on one side of the road. <...> On mounting a rising ground, which brought the figure of his fellow-traveller in relief against the sky, gigantic in height, and muffled in a cloak, Ichabod was horror-struck on perceiving that he was headless! - but his horror was still more increased on observing that the head, which should have rested on his shoulders, was carried before him on the pommel of his saddle!” [Ibidem]. Богатырское, крепкое телосложение, плащ, богатырский черный конь, отсеченная голова - все также говорит нам о том, что Всадник без головы - это трансформированный и «темный» вариант образа Зеленого Рыцаря, который описывается в подобном ключе в поэме «Сэр Гавейн и Зеленый Рыцарь».

Следует отметить сходства, которые мы наблюдаем в образах Зеленого Рыцаря из поэмы «Сэр Гавейн и Зеленый Рыцарь» и Всадника без головы из новеллы В. Ирвинга «Легенда о Сонной Лощине»: 1) цикличность (появление в «темное» время Колеса года и в темное время суток); 2) высокий рост (схожесть с великаном) и крепкий конь; 3) отсеченная голова; 4) топологическая соотнесенность с лесом, полным густых деревьев; 5) отсутствие враждебного настроя (ни Всадник без головы, ни Зеленый Рыцарь не нападают без повода).

Обращение к таким сходствам акцентирует внимание лишь на цвете одежды и коня, что связано с заимствованием элементов из ирландских легенд о Дюллахане, чей образ мы также рассмотрели в контексте анализа Зеленого Рыцаря из поэмы «Сэр Гавейн и Зеленый Рыцарь».

\section{Заключение}

Следует сделать вывод, что образ Зеленого человека и похожих мужских божеств имеет определенные характеристики в фольклоре Британских островов; так, например, образ Кернунна всегда связан с циклами времен года, от чего зависит его репрезентация в легендах и мифах (Дуб и Падуб), всегда обладает ветвистыми рогами и имеет отношение к охоте и плодородию (Луг), богато одет с преобладанием зеленого цвета (Зеленый человек). Данные факты обращают нас к подобному образу в поэме «Сэр Гавейн и Зеленый Рыцарь», который заимствует, помимо характеристик Зеленого человека, черты Дюллахана, Всадника без головы. Так, в дальнейшем в литературе черты Дюллахана в эклектичном соединении с образом Кернунна становятся основой для фольклорных образов в произведениях «Виндзорские насмешницы» У. Шекспира, «Виндзорский замок» У. Х. Эйнсворта и «Легенда о Сонной Лощине» В. Ирвинга.

В ходе проделанной работы открывается перспектива для дальнейшего исследования литературы англоязычных стран с целью выявления трансформаций образа Кернунна в художественных текстах эпохи романтизма и современной литературе жанра фэнтези и хоррора. 


\section{Источники | References}

1. Волконская М. А. Первая строфа поэмы «Сэр Гавейн и Зеленый Рыцарь»: язык и темы [Электронный ресурс] // Атлантика. Записки по исторической поэтике: сб. к 75-летию О. А. Смирницкой / под ред. Т. А. Михайловой. М.: Издательство Московского университета, 2013. Вып. XI. C. 75-85. URL: https://publications. hse.ru/chapters/101083630 (дата обращения: 27.06.2021).

2. Вышенская Ю. П. Аспекты соприкосновения языкового и неязыкового в процессе формирования художественного стиля (на материале поэмы “Sir Gawain and the Green Knight”) [Электронный ресурс] // Филологические науки. Вопросы теории и практики. 2016. № 7 (61). Ч. 2. URL: https:/www.gramota.net/materials/ 2/2016/7-2/22.html (дата обращения: 27.06.2021).

3. Кельтские мифы и легенды / сост. О. Крючкова. М.: Э, 2017. 96 с.

4. Тресиддер Дж. Словарь символов [Электронный ресурс]. URL: https:/www.booksite.ru/localtxt/tre/sid/der/ tresidder_d/slovar_sim/index.htm (дата обращения: 27.06.2021).

5. Фрезер Дж. Золотая ветвь [Электронный ресурс]. URL: http://opentextnn.ru/man/frezer-dzhejms-zolotaja-vetv/ (дата обращения: 27.06.2021).

6. Шарапкова А. А. Языковые особенности репрезентации власти в романе Т. Мэлори «Смерть Артура»: гендерный аспект [Электронный ресурс]. URL: https://istina.msu.ru/publications/article/8845081/(дата обращения: 01.07.2021).

7. Alexander Sh. Lugh, Master of Skills [Электронный ресурc]. URL: https://thecelticjourney.wordpress.com/ 2013/06/16/lugh-master-of-skills/(дата обращения: 01.07.2021).

8. Green M. Celtic Art: Reading the Messages. L.: Weidenfeld \& Nicolson, 1996. 176 p.

9. Haggerty B. The Dullahan - Ireland's Headless Horseman [Электронный ресурc]. URL: http://www.irishcultureand customs.com/ACalend/Dullahan.html (дата обращения: 01.07.2021).

10. Hutton R. The Wild Hunt in the Modern British Imagination // Folklore. 2019. Vol. 130. Iss. 2. P. 175-191.

11. Irving W. The Legend of Sleepy Hollow [Электронный ресурc]. URL: https://www.gutenberg.org/files/41/41h/41-h.htm (дата обращения: 03.07.2021).

12. Lugus [Электронный ресурс] // Encyclopedia Britannica. URL: https://www.britannica.com/topic/Lugus (дата обращения: 01.07.2021).

13. MacCana P. Celtic Mythology [Электронный ресурс]. URL: https://archive.org/details/celticmythology00macc (дата обращения: 29.06.2021).

14. Paris W. "Heroic Struggle": A Medieval and Modern Dilemma // Journal of Religion and Health. 1988. Vol. 27. № 2. P. 143-153.

15. Reagan R. Who Is the Horned God? [Электронный pecypc]. URL: https://blackthornandstone.com/ 2020/04/23/who-is-the-horned-god-a-journey-from-ancient-deer-goddess-cult-to-pop-culture/(дата обращения: 27.06.2021).

16. Simos M. The Spiral Dance by Starhawk [Электронный ресурс]. URL: https://static1.squarespace.com/static/ 562a01bae4b05e6cc1f31568/t/573b484459827e6e7a571ca6/1463502939829/starhawk_-_spiral_dance.pdf (дата обращения: 01.07.2021).

17. Simpson J. Seeking the Lore of the Land // Folklore. 2008. Vol. 119. Iss. 2. P. 131-141.

18. Sir Gawain and the Green Knight [Электронный ресурc]. URL: https:/quod.lib.umich.edu/c/cme/Gawain/ 1:1?rgn=div1;view=fulltext (дата обращения: 29.06.2021).

19. Traynor J. How tales of the headless horseman came from Celtic mythology [Электронный ресурс]. URL: https:/www.irishtimes.com/life-and-style/abroad/how-tales-of-the-headless-horseman-came-from-celticmythology-1.4060086 (дата обращения: 03.07.2021).

\section{Информация об авторах | Author information}

RU Чемезова Екатерина Рудольфовна ${ }^{1}$, к. филол. н.
${ }^{1}$ Гуманитарно-педагогическая академия (филиал)

Крымского федерального университета им. В. И. Вернадского, г. Ялта

EN Chemezova Ekaterina Rudolfovna ${ }^{1}, \mathrm{PhD}$

${ }^{1}$ Humanities and Education Science Academy (branch) of V. I. Vernadsky Crimean Federal University, Yalta

${ }^{1}$ chemezova4@gmail.com

\section{Информация о статье | About this article}

Дата поступления рукописи (received): 17.07.2021; опубликовано (published): 15.09.2021.

Ключевые слова (keywords): Кернунн; Зеленый человек; артурианские легенды; В. Ирвинг; У. Шекспир; Cernunnos; Green Man; Arthurian legends; W. Irving; W. Shakespeare. 